\title{
LA HUIDA DE UN REY. \\ REFLEJOS DE UN MOSAICO POMPEYANO EN LAS \\ VERSIONES DE ALEJANDRO DE ROBERT ROSSEN \\ (1956) Y OLIVER STONE (2005)
}

\author{
A KING'S RUNAWAY. \\ REFLECTIONS OF A POMPEII'S MOSAIC IN ROBERT \\ ROSSEN'S ALEXANDER (1956) AND OLIVER \\ STONE'S (2005)
}

Víctor Mínguez

Universitat Jaume I

\section{RESUMEN}

La batalla de Qadesh (1274 a.C.), la más importante de la Edad del Bronce y el mayor combate de carros de la Historia, fue narrada por los dos imperios contendientes -el egipcio y el hitita- como una victoria, hasta el punto de que seguimos sin saber a día de hoy quien ganó realmente. Quizá por eso la imagen que condensa la batalla más decisiva del mundo antiguo hasta la aparición de Roma, Isso (333 a.C.), que enfrentó a Alejandro de Macedonia con Darío de Persia, es la recreación de la huida del monarca aqueménida en su carro ante la carga decidida del joven macedonio. Huida que volvió a repetirse de manera casi idéntica dos años después en la batalla de Gaugamela (331 a.C.). El maravilloso mosaico romano hallado en la pompeyana Casa del Fauno (120-100 a.C. Museo Nazionale Archeologico, Nápoles) capta con gran belleza este instante bélico -ya se trate de Isso o de Gaugamela- que acredita una victoria indiscutible. La huida de Darío en Gaugamela supone también el clímax de las dos películas sobre Alejandro rodadas por Robert Rossen (1956) y Oliver Stone (2005). Como en las imitatio Alexandri de la Antigüedad, o en las pinturas modernas de Brueghel, Altdorfer, Pietro de Cortona o Le Brun, Rossen y Stone construyen el mito de Alejandro sobre este instante preciso que determina de forma clara el destino del héroe.

Palabras clave: Alejandro, Isso, Gaugamela, Robert Rossen, Oliver Stone.

\section{ABSTRACT}

LThe battle of Qadesh (1274 BC), the most important one of the Bronze Age and the greatest chariots battle of the History, was narrated by the two warring empires -the Egyptian and Hittite- as a victory, to the point that we still do not know today who really won. Perhaps that's why the image that condenses the 
most decisive battle of the Ancient World until the appearance of Rome, Issos (333 BC), which confronted Alexander of Macedonia with Darius of Persia, is a recreation of the flight of the Achaemenid monarch riding his chariot before the the young Macedonian's determined charge. That runaway would be almost identically repeated two years later, in Gaugamela's Battle (331 BC). The wonderful roman mosaic founded in the Pompeiian House of the Faun (120-100 BC, Museo Nazionale Archeologico, Nápoles) captures with great beauty this instant of war -whether Issos or Gaugamela- which accredits an indisputable victory. It also implies the climax of the film Alexander (Oliver Stone, 2005): in the film, once the Battle of Gaugamela has ended with the fearful flight of Darius, the city of Babylon - a cyclorama of fifty meters long created by artist Steve Mitchell- welcomes the brave triumphant conqueror. As in the imitatio Alexandri of antiquity, or in the modern paintings by Brueghel, Altdorfer, Pietro da Cortona or Le Brun, Stone constructs the myth of Alexander on this precise moment which clearly determines the hero's fate.

Key-words: Alexander, Issos, Gaugamela, Robert Rossen, Oliver Stone.

\section{RESUM}

\section{La fugida d'un rei. Reflexos d'un mosaic pompeià a les versions d'Alejandro de Robert Rossen (1956) i Oliver Stone (2005)}

La batalla de Qadesh (1274 a.C.), la més important de l'Edat del Bronze i el combat més gran de carros de la Història, fou narrada pels dos imperis contendents -l'egipci i l'hitita- com una victòria, fins el punt que a dia d'avui seguim sense saber qui va guanyar realment. Potser per això, la imatge que condensa la batalla més decisiva del món antic fins l'aparició de Roma, Issos (333 a.C.), que enfrontà Alexandre de Macedònia amb Darío de Persia, és la recreació de la fugida del monarca aquemènida en el seu carro front la decidida càrrega del jove macedoni. La fugida es reproduirà de forma pràcticament idèntica dos anys després en la batalla de Gaugamela (331 a.C.). El meravellós mosaic romà trobat a la pompeiana Casa del Faune (120-100 a.C. Museo Nazionale Archeologico, Nàpols) capta amb gran bellesa aquest instant bèl.lic -sigui Issos o Gaugamela- que acredita una victòria indiscutible, i suposa també el clímax de la pel.lícula Alexander, d'Oliver Stone (2005): en el film i finalitzada la batalla de Gaugamela amb la fugida atemorida de Darío, Babilonia -un ciclorama de cinquanta metres de llarg creat per l'artista Steve Mitchell- rep triomfant al valent conqueridor. Com a les imitatio Alexandri de l'Antiguitat, o les pintures modernes de Brueghel, Altdorfer, Pietro de Cortona o Le Brun, Stone construeix el mite d'Alexandre sobre aquest instant precís que determina de forma clara el destí de l'heroi.

Paraules clau: Alejandro, Isso, Gaugamela, Robert Rossen, Oliver Stone. 
De las numerosas campañas militares de la Antigüedad ninguna fue tan decisiva como la que emprendió Alejandro de Macedonia en el año 334 a.C. contra el imperio Persa, pues alteró todas las fronteras y equilibrios del mundo conocido, supuso la supremacía de Occidente sobre Oriente durante siglos y fue el origen del nacimiento de la poderosa cultura helenística. Ni siquiera las victorias de Aníbal, Pompeyo, César o Trajano tuvieron el impacto estratégico de las de Alejandro, que convirtieron a éste en el gran conquistador del pasado y en el referente insuperable de todos los que vinieron después. De las diversas batallas que jalonaron su ordalía-Gránico, Tiro, Hidaspes- dos de ellas fueron decisivas, Isso (333 a.C.) y Gaugamela (331 a.C.) -ésta última también llamada de Arbela-, y sorprendentemente semejantes, hasta el punto que muchas veces se han confundido las representaciones artísticas de ambas: tanto en Isso como en Gaugamela el ejército greco-macedonio de Alejandro se enfrentó a fuerzas muy superiores de Darío III, formadas por contingentes procedentes de todos los territorios del gran imperio de los persas de la dinastía Aqueménida. En ambos casos la valiente carga de Alejandro en el momento decisivo del combate contra el centro del ejército persa puso en fuga a Darío. La relevancia de Isso estriba en que fue la primera vez que se encontraron frente a frente Alejandro y Darío a ambos márgenes del río Pinaro, y por lo tanto la sorpresa por el valor del primero y la cobardía del segundo fue mayor. La trascendencia de Gaugamela deriva de que el combate se desarrolla dos años después que el primero ante las puertas de Babilonia, y ya no va a ver una tercera oportunidad.

La primera gran batalla terrestre del pasado fue la de Qadesh (1274 a.C.), librada entre el faraón Ramsés II y el rey hitita Muwatalli II, primera contienda documentada de la Historia, en la que ambos bandos reclamaron la victoria y todavía hoy en día hay incerteza sobre su resultado real más allá de la propaganda. Otras batallas anteriores o posteriores a la campaña de Alejandro sí resultaron claramente decisivas, como Maratón (490 
a.C.), Platea (479 a.C.), Cannas (216 a.C.), Alesia (52 a.C.) o Farsalia (48 a.C.). Todas han sido, en algún momento, recreadas en el cine, y todas con resultados muy mediocres. En el cine de $35 \mathrm{~mm}$, y particularmente en la época del Peplum de los años setenta-caso por ejemplo de Maratón (La battaglia di Maratona, Jacques Tourneur, 1959), Cannas (Annibale, Carlo Ludovico Bragaglia y Edgar G. Ulmer, 1959) o Alesia (Giulio Cesare, il conquistatore delle Gallie, Tanio Boccia, 1962)- la falta de presupuesto, la ausencia de rigor y la ingenuidad del guion impidieron siempre resultados aceptables. Batallas que implicaban decenas de miles de hombres se resolvían con planos en los que apenas aparecían unos cientos; la indumentaria, el armamento, los peinados y el maquillaje parecían extraídos de una tienda de disfraces; el montaje solía ser confuso; y los anacronismos constantes. La censura a la hora de representar la violencia implícita en la guerra acababa convirtiendo la recreación bélica en una torpe coreografía dirigida a un público infantil, desinformado o poco exigente. Y no era solo cuestión de presupuesto: la muy digna The fall of the Roman empire (1964), de Anthony Mann y producida por Samuel Bronston acabó primando la espectacularidad sobre la verosimilitud. Solo dos películas que representan por estos años batallas terrestres de la Antigüedad sobresalen claramente entre tanta mediocridad, y no es casual que ambas fueran dirigidas por grandes maestros del cine: Stanley Kubrick, que recreó la batalla del río Silario entre Craso y Espartaco (Spartacus, 1960), y Joseph L. Mankiewicz, que rodó la batalla de Farsalia (Julius Caesar, 1953). En realidad se trata dos películas políticas prodigiosas, ambientadas en conflictos civiles, en las que los combates no son más que una pieza más en una obra de arte perfecta en la que el guion, los diálogos, la música, la dirección de actores, los decorados y otros elementos cinematográficos son tan sobresalientes como los propios combates. Pese a esto, la batalla final entre las legiones romanas y el ejército de esclavos y gladiadores en la película de Kubrick constituye sin duda la mejor recreación cinematográfica de un enfrentamiento masivo en el mundo antiguo. Hay alguna película más del siglo XX ambientada en la Antigüedad que roza la perfección, como Pharaoh (1966), de Jerzy Kawalerowicz, pero aunque espectacular, en ella las batallas campales no tienen relevancia.

Las batallas terrestres rodadas ya por el cine del siglo XXI, también con alguna excepción, han sido en general muy decepcionantes. Dos películas finiseculares, Braveheart (1995), de Mel Gibson -ambientada ya en la Baja Edad Media, pero con dos excelentes batallas campales, Stirling y Falkirk-, y Gladiator (2000), de Ridley Scott, hicieron concebir muchas expectativas futuras. Fueron alabadas por la crítica y obtuvieron cada una cinco premios Oscar de la Academia americana respectivamente. En am- 
bas el rigor en el recreacionismo bélico es evidente, los movimientos de masas resultan visualmente perfectos, y la violencia aflora sin censura. Sin embargo, el infantilismo y el maniqueísmo que se impuso en el cine mainstream tras los atentados en Nueva York del 11 de Septiembre, y la llegada del cine en formato digital -de enormes posibilidades pero también de indudables peligros- dieron al traste con las expectativas creadas. Si antes las batallas resultaban poco convincentes por el escaso número de extras, ahora las multitudes abrumarían por exceso, como en la por otra parte excelente Troy, de Wolfgang Petersen (2004). Y en otras la complacencia en la violencia alcanza el género gore, caso de 300, de Zack Snyder (2006). En esta última se recrean las batallas de Termópilas y Platea con una estética comic que trivializa el relato. Pero es mucho peor cuando son las influencias estéticas del videojuego o del videoclip las que se superponen al lenguaje cinematográfico, con resultados que es mejor olvidar. Hay algunas películas que han pretendido mantener un cierto rigor histórico pero donde el conflicto entre el cine tradicional y los recursos digitales ha acabado produciendo una impostura, como en las batallas de Gergovia - Alesia de la película Druids, de Jacques Dorfmann (2001), perjudicada además por una nefasta selección de actores. Y otras más numerosas que directamente abrazan la irreverencia histórica contemporánea, como Exodus: goods and kings, de Ridley Scott (2014): aunque centrada en el relato bíblico se inicia con una supuesta recreación de la batalla de Qadesh en la que los egipcios poseen carros y los hititas no.

Curiosamente las batallas navales de la Antigüedad han tenido un mejor tratamiento en el cine, con tan poco rigor como las batallas terrestres, pero con mucha más espectacularidad, habiendo dejado en la retina de sucesivas generaciones de espectadores escenas bélicas inolvidables. No han sido muchas, pues su rodaje resultó siempre mucho más caro que el de sus homólogas en tierra. El mejor ejemplo cinematográfico de batalla naval antigua es la campaña contra los piratas cilicios, representada en un episodio central de las tres versiones de Ben-Hur (Fred Niblo, 1925; William Wyler, 1959; y Timur Bekmambetov, 2016). La más interesante curiosamente es la rodada por Niblo -segunda versión en cine mudo de la novela de Lew Wallace tras otra filmada en 1907, en parte en el estudio de la Metro-Goldwyn-Mayer y en parte en el puerto italiano de Livorno, con escenas rebosantes de la teatralidad propia del cine de estos años pero también con convicción y belleza. También podemos citar con admiración la batalla de Accio rodada por Joseph L. Mankiewicz para Cleopatra (1963). Por su parte el formato digital ha aportado hasta el momento la recreación de Salamina en 300. Rise of an Empire, de Noam Murro (2014), que adolece de los mismos defectos de su precuela ya mencionada. 
Cuatro directores han rodado biopics sobre Alejandro Magno: Sohrab Modi (Sikandar, 1941), Robert Rossen (Alexander the Great, 1956), Theo Angelopoulos (Megalexandros, 1980) y Oliver Stone (Alexander, 2004).' La película de Modi se centra en la batalla entre Alejandro y el rey indio Poro en el río Hidaspes, y está considerada una muestra de cine patriótico de la compañía Minerva Movietone. La de Angelopoulos, ganadora del León de Oro en el Festival de Venecia, supone una contemporización del mito de Alejandro reencarnado en un bandido del siglo XX. ${ }^{2}$ Ambas ignoran por lo tanto las batallas de Isso-Gaugamela, objeto de mi interés en esta ocasión. Mi intención por ello es centrarme en las películas de Rossen y Stone, como recreadores visuales de la batalla de Gaugamela. Y destacar en qué medida su recreación del combate es heredero de la única imagen de la misma que ha sobrevivido de la Antigüedad clásica: el mosaico pompeyano encontrado en la Casa del Fauno, en cuanto que éste, desde que fue descubierto en la primera mitad del siglo XIX, estableció la imagen oficial del duelo entre Alejandro y Darío, ya fuera a orillas del Mediterráneo o a las puertas de Babilonia.

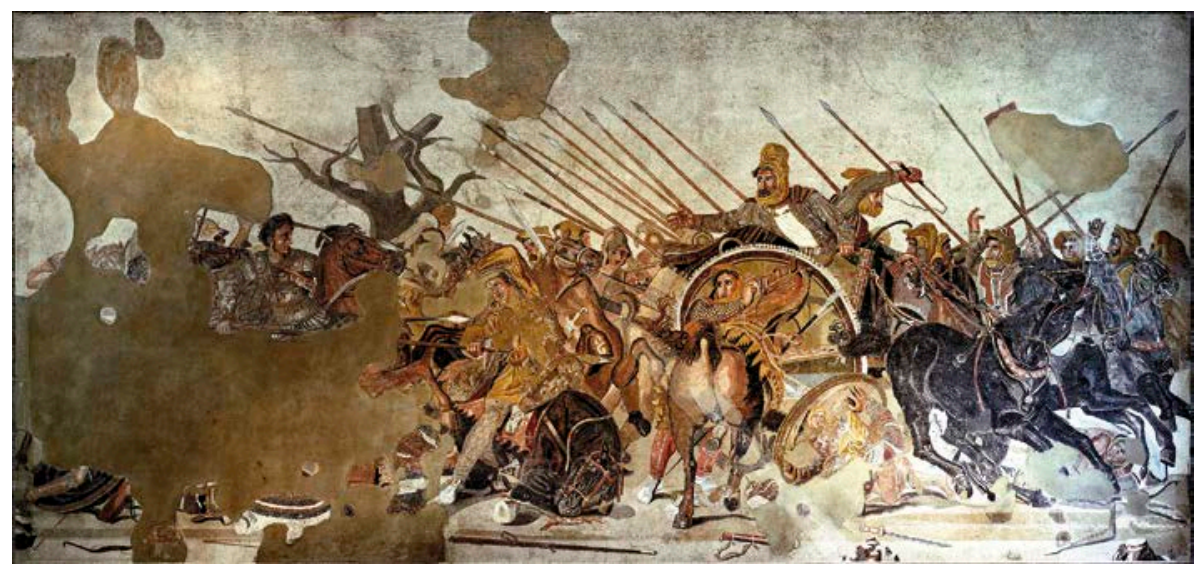

Fig.- 1. Mosaico de Casa del Fauno, con la carga de Alejandro y la huida de Darío.

1 ALBERICH, Enric (2009), Películas clave del cine histórico, Robin Book, Barcelona.

2 GÓMEZ ESPELOSÍN, Francisco Javier (2007), La Leyenda de Alejandro. Mito, historiografía y propaganda, Universidad de Alcalá, Alcalá de Henares, pp. 418-420. 
Rossen produjo su película para United Artists, con su propio guión y dirección, y música de Mario Nascimbene. Autoexiliado a causa del Comité de Actividades Antiamericanas rodó en España, con Richard Burton como protagonista -varios años antes de encarnar éste a Marco Antonio en la película Cleopatra dirigida por Mankiewicz (1963)-. A Burton le acompañaron en el reparto Fredric March, Claire Bloom, Danielle Darrieux, Marisa de Leza y Stanley Baker. Pero la United Artists redujo el montaje del director perjudicando al filme notablemente. Por su parte Stone rodó su versión -coproducida por Estados Unidos, Alemania, Países Bajos, Francia y Reino Unido- en Marruecos, Londres, Tailandia y el Himalaya. Costó ciento quince millones de dólares. Pero aunque recaudó doscientos se consideró un fracaso comercial -en Estados Unidos solo obtuvo treinta y cuatro millones de esa cantidad-y no recibió buenas críticas. ${ }^{3}$ El guión -la vida de Alejandro narrada por Ptolomeo l- es del propio Stone junto a Christopher Kyle y Laeta Kalogridis, con el asesoramiento histórico de Robin Lane Fox, profesor de historia clásica en Oxford y autor de una reconocida biografía del conquistador macedonio, Alexander the Great (Penguin, 2004). ${ }^{4}$ La música fue compuesta por Vangelis. Alejandro fue interpretado por Colin Farrell, acompañado en los principales papeles por Angelina Jolie, Val Kilmer, Anthony Hopkins y Christopher Plummer.

La fascinación por el personaje de Alejandro no es solo actual, como podría parecer si nos atenemos al gran número de novelas y biografías centradas en él publicadas estas últimas décadas. Arrancó ya en vida del conquistador y ha seguido creciendo durante siglos hasta el presente. Sus sorprendentes e incuestionables conquistas lo convirtieron en modelo de estrategas y emperadores, desarrollándose ya en la Antigüedad lo que se llamó la imitatio Alexandri, que practicaron ansiosos los más grandes estadistas como Escipión el Africano, Pompeyo, Craso, Julio César, Marco Antonio, Augusto o Trajano. ${ }^{5}$ No obstante, conviene advertir que el deslumbramiento que provoca el gran macedonio a quienes se aproximan a su figura y a su obra no ha sido constante a lo largo de los siglos, y ni mucho menos unánime. Incluso en la Roma de los césares en la que su recuerdo estaba muy próximo e inspiraba a sus más famosos generales como los mencionados César, Marco Antonio o Augusto, su persona fue criticada

3 Para congraciarse con el público americano rodaría a continuación World Trade Center (2006), un filme de contenido patriótico centrado en los atentados del 11 de septiembre de 2001.

4 Ha sido publicada en castellano: LANE FOX, Robin (2007), Alejandro Magno. Conquistador del Mundo, Acantilado, Barcelona.

5 GÓMEZ ESPELOSÍN, La Leyenda de Alejandro, pp. 386 y 387. 
por autores como Cicerón, Séneca o Lucano a causa de su ambiguo comportamiento moral. Siglos después, en la Francia prerrevolucionaria, y a pesar de contar con la simpatía de Voltaire o Montesquieu, los intelectuales críticos con el sistema absolutista despreciaron a Alejandro porque veían en él la mejor reencarnación del régimen que detestaban. Francisco Javier Gómez explica este posicionamiento hostil de los círculos revolucionarios por el desprestigio que alcanzaron en la Edad Moderna los últimos años de la vida de Alejandro, caracterizados según algunas fuentes por la tiranía, la autodivinización y el desenfreno. ${ }^{6}$ Incluso Napoleón, que emprendió en 1798 la campaña de Egipto siguiendo las huellas del macedonio-acompañándose como él de sabios y científicos, y cruzando luego a Asia en una clara imitación al Magno-, hizo una valoración negativa del personaje: en el Memorial de Santa Elena Enmanuel Las Cases recoge palabras críticas del emperador de Francia hacia Alejandro a causa de su degradación moral, afirmando preferir como modelo a Julio César. ${ }^{7}$ Probablemente, el general Bonaparte admiró al Alejandro conquistador, mientras que el emperador Napoleón lo vio como un referente peligroso de su propia ambición. Por citar una última opinión crítica, el propio Chateaubriand despreciaba a Alejandro por considerarlo un precedente de su primero admirado y luego estigmatizado Napoleón. ${ }^{8}$ Esa dualidad compleja del personaje histórico intentaron recrearla en el cine tanto Rossen como Stone, mostrando en ambos casos a un personaje conflictivo y torturado que evoluciona hacia el vicio, el poder absoluto y la locura.

Pero recordemos ahora los elementos claves de la campaña militar que centra nuestro interés, conocidos fundamentalmente a través de tres autores clásicos: Plutarco (Vida de Alejandro), Quinto Curcio Rufo (De los hechos de Alejandro Magno de Macedonia), y Flavio Arriano (Anábasis de Alejandro Magno). Las batallas de Isso y Gaugamela se enmarcan en la conquista del imperio persa que emprendió Alejandro el año 334 a.C. Tras cruzar el Helesponto al frente de treinta mil infantes y cinco mil jinetes, el rey de Macedonia se enfrentó por primera vez al ejército persa en Gránico, en la que fue su primera victoria en Asia. Tras la misma, Alejandro avanzó con

6 GÓMEZ ESPELOSIN, La Leyenda de Alejandro, pp. 386-395. Véase también MOSSÉ, Claude (2004), Alejandro Magno. El Destino de un Mito, Espasa, Madrid; y BOSWORTH, Albert Brian (1996), Alexander and the East. The tragedy of triumph, Oxford University Press, Oxford.

7 GÓMEZ ESPELOSIN, La Leyenda de Alejandro, pp. 386-396.

8 MÍNGUEZ, Víctor y RODRÍGUEZ MOYA, Inmaculada (2014), Napoleón y el espejo de la Antigüedad. Arqueología de las imágenes del poder, Universitat de València, Valencia, pp.43 1 . 435. 
su ejército a través de Asia Menor liberando y ocupando ciudades -Sardis, Éfeso, Mileto, Halicarnaso- y desplazándose hacia Siria. La derrota persa en Gránico y la posterior muerte del almirante Memnón que lideraba la resistencia contra Alejandro obligaron al emperador aqueménida a intentar resolver personalmente la crisis. Darío III reunió en Babilonia un gran ejército con el que avanzó hasta la ciudad costera de Isso, en los límites entre Cilicia y Siria, para reunirse con la flota persa que aun operaba en el Mediterráneo y cortar de este modo las comunicaciones de Alejandro con sus bases. Una vez conquistada la urbe, Darío esperó a su enemigo junto al río Pínaro en noviembre del 333 a.C. Como en muchas de las batallas de la Antigüedad, las cifras de combatientes son muy dispares según las diversas fuentes, pero todas coinciden en la aplastante superioridad numérica persa, aunque hay que reconocer que ésta quedó limitada por una estrecha llanura entre el mar y las montañas Amanos que impidió a Darío desplegar todas sus fuerzas. El inteligente movimiento estratégico del rey persa al situarse a espaldas de Alejandro cortando sus suministros se convirtió en una trampa mortal cuando éste se dio la vuelta y se inició la batalla: aunque las fuerzas macedonias sufrieron en su ala izquierda un duro ataque de la caballería persa, una temprana e inesperada carga liderada por el propio Alejandro al frente de los Hetairoi o "compañeros" en el centro de la contienda provocó la confusión en el ejército babilónico, convirtiéndose en retirada cuando el propio Gran Rey emprendió una acelerada huida en su carro -precipitada en realidad por cuanto la batalla aún no estaba resuelta-. Las cifras de bajas también oscilan de forma dispar. El combate, aunque empeñó dos grandes ejércitos y fue muy violento, se resolvió en apenas unas horas, y tuvo lugar en un luminoso día otoñal. ${ }^{9}$

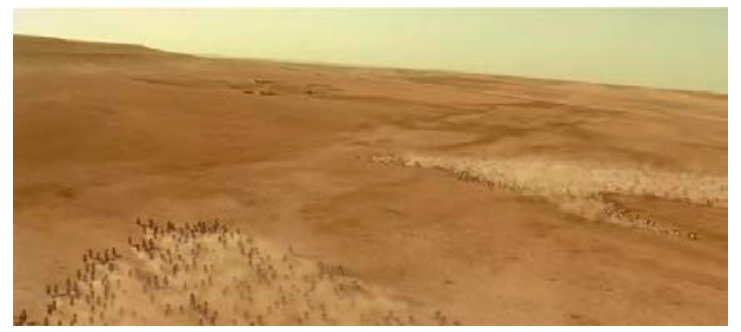

Fig.- 2. Alejandro se desmarca al frente de los Heitaroi hacia el centro de la batalla (derecha) en busca de Darío mientras sus tropas siguen avanzando hacia la izquierda, seguidas por los persas (Stone, 2004).

9 WARRY, John (1994), Alejandro 334-323 A.C. La conquista del imperio persa, Ediciones del Prado, Madrid, p. 38. 
El impacto de la batalla de Isso en todo el mundo conocido fue tremendo una vez se difundió el resultado y con consecuencias inmediatas: la flota persa del Mediterráneo, compuesta por embarcaciones jonias, fenicias y chipriotas se disolvió, los griegos que seguían oponiéndose a Alejandro dejaron de hacerlo -con la excepción de Esparta que mantuvo su resistencia-, y el dominio de éste sobre los territorios al oeste del Éufrates fue indiscutible, cayendo en sus manos durante los meses siguientes Siria, Fenicia y Egipto. ${ }^{10}$ Como destacó Fernando de Olaguer-Feliú, dos episodios de la batalla tuvieron gran trascendencia en el relato posterior de la misma: la cobardía de Darío III al huir frente a la carga de Alejandro y la clemencia y generosidad de éste con los familiares capturados del primero -la reina madre Sisigambis, la emperatriz Estatira, y los hijos de Darío y Estatira: el príncipe heredero Oco, y las princesas Estatira y Drypetis-, dos anécdotas que perfilaron dos comportamientos muy distintos en ambos líderes y que los retrataron ya de manera irreversible ante sus contemporáneos. ${ }^{11} \mathrm{~A}$ partir de Isso ya nada sería igual en la guerra macedonia contra el imperio persa. Si incluso tras la batalla de Gránico, la expedición militar de Alejandro era contemplada desde Babilonia como una aventura sin posibilidades de tener éxito ante la grandeza del imperio de Darío -heredero de Ciro el Grande-, y la inmensidad de su poder, tras Isso todo fue distinto: un enorme ejército había sido derrotado por una fuerza inferior y el Rey de Reyes había huido humillado del campo de batalla. Una vez a salvo en el Éufrates, Darío envío una carta conciliadora a Alejandro proponiéndole la paz, pero éste la rechazó exigiéndole una rendición incondicional con el propósito de que a su vez Darío se negara y poder prolongar así la campaña militar. Posteriormente, y durante el asedio de Tiro, Alejandro recibió una segunda carta de Darío en la que éste le ofrecía todo el territorio al oeste del Éufrates y el matrimonio con su hija, carta que tampoco conmovió al macedonio. De manera evidente y como explica John Warry, la estrategia de Alejandro pasaba por hacer la guerra fuera de Grecia para mantener la paz en casa. ${ }^{12}$

En cualquier caso y desde Isso la superioridad personal de Alejandro se reafirmó y su prestigio aumentó considerablemente, invirtiendo la suerte de la guerra de forma irremediable como comprobaría apesumbrado Darío III tres años después en la posterior y definitiva batalla de Gaugamela

10 BARCELÓ, Pedro (2011), Alejandro Magno, Alianza, Madrid, pp. 159 y 160.

11 OLAGUER-FELIÚ Y ALONSO, Fernando de (2000), Alejandro Magno y el Arte, Encuentro, Madrid, pp. 26-28.

12 WARRY, Alejandro 334-323 A.C, pp. 40 y 48. 
(octubre del 331 a.C.) -aldea próxima a Nínive y ya en el camino hacia las puertas de Babilonia-, donde de nuevo el Rey de Reyes huyó de otra impetuosa carga de Alejandro y sus compañeros, perdiendo ahora ya sí irremediablemente el trono. De nuevo las fuentes esenciales son los relatos ya mencionados de Plutarco, Curcio y Arriano. En esta ocasión, el una vez más mayor ejército aqueménida sí que pudo desplegarse en la llanura sobrepasando los flancos del de Alejandro. Darío incluso había ordenado nivelar el campo de batalla para facilitar los movimientos de sus carros y su caballería. El ataque lo iniciaron los carros falcados contra la falange macedónica pero fueron frenados por los proyectiles de la infantería ligera. Mientras, Alejandro desplazó su ala derecha hacía un terreno menos nivelado obligando al persa a hacer lo mismo con su izquierda. Darío ordenó un ataque general, provocando una brecha en su centro que Alejandro aprovecho audazmente con una carga de caballería e infantería en formación de cuña desde su desplazada ala derecha contra la guardia personal de Darío. Éste no tardó en replegarse desmoralizando a su ejército y perdiendo la batalla. ${ }^{13}$

Antes de analizar la recreación de la batalla de Gaugamela en ambas películas quiero trazar un itinerario visual de la misma, desde la Antigüedad hasta nuestro días, para determinar como la carga de Alejandro en los dos filmes no solo responde a los relatos escritos de la batalla, sino a un imaginario que ha pervivido a lo largo de los siglos debido al carisma del personaje y a su indudable trascendencia histórica como modelo a imitar por todos los militares, reyes, emperadores y conquistadores posteriores. Un imaginario que se inicia ya en época helenística, y que tiene su representación más famosa en el mencionado mosaico pompeyano. Según las fuentes clásicas hubo muchas representaciones de la batalla de Isso en la Antigüedad. Así, sabemos por ejemplo que en el siglo IV a.C. diversos pintores helenísticos la recrearon, como Arístides de Tebas, Helena de Alejandría y Filoxenos de Eretria. ${ }^{14}$ Pero prácticamente todas se perdieron en el tiempo. Esta circunstancia, y su indudable calidad artística es lo que hace tan relevante el mosaico hallado en las excavaciones arqueológicas de Pompeya, La Batalla de Isso -o quizá Gaugamela-, procedente de la Casa del Fauno (120-100 a.C. Museo Arqueológico Nacional de Nápoles), y que copia probablemente alguna pintura perdida de Apeles, o del

13 PENDERSON, Robert B. (2015), A study of combined arms warfare by Alexander the Great, Penny Hill Press, Lexington.

14 OLAGUER-FELIÚ, Alejandro Magno, p. 103. 
mencionado Filoxenos de Eretria, que según Plinio pintó una Batalla de Alejandro con Darío entre los años 319 y 297 a.C., encargada por el diádoco Casandro para su Palacio Real en Macedonia. ${ }^{15}$ En cualquier caso, un original de un tiempo en que la victoria aún estaba reciente.

Antonio García Bellido ya lo consideró el más importante de los mosaicos pompeyanos, y opinó que efectivamente copiaba un original de finales del siglo III a.C., pero que probablemente fue montado en el pavimento de esta casa y no traído de ningún otro sitio. Mide más de 5 metros de largo por 2,7 de ancho, y reúne millón y medio de teselas de 2 a 3 milímetros dispuestas según la técnica de opus vermiculatum. Las teselas más grandes corresponden a una mala restauración tras la erupción de Vesubio del año 63 y antes de la devastación del 79 que lo ocultó definitivamente durante siglos. ${ }^{16}$ Algunas partes han desaparecido por completo. A la izquierda se sitúan los griegos y a la derecha los persas, y en el centro el tronco de un árbol seco que ejerce de eje divisorio. La parte más deteriorada representa la carga de la caballería macedonia, de la que por suerte se ha salvado el rostro y la mayor parte del cuerpo de Alejandro: éste viste armadura griega decorada con la Gorgona, espada ceñida y capa, lleva la cabeza descubierta y sostiene con una mano la lanza con la que atraviesa a un persa caído, sobre el que Bucéfalo agita sus patas encabritadas. El grupo aqueménida se ha conservado mucho mejor: jinetes, infantes y lanzas rodean el carro de Darío, huyendo todos del rey macedonio en un tropel confuso. Pero es en los rostros más que en las actitudes donde percibimos de qué lado se inclina la victoria: la determinación irrefrenable de Alejandro; el espanto desorbitado en Darío y sus hombres. La intensidad psicológica de la dramática escena queda reforzada por un magnífico dominio de la perspectiva-el caballo que vemos de grupas o el que permanece herido en el suelo-, los juegos especulares -un soldado ve su propia muerte reflejado en un escudo y un precioso uso del color -con predominio de amarillos, ocres, rojos y azules-, que convierten a esta obra artística en una de las más relevantes de la Antigüedad.

El mosaico pompeyano no lo conocieron los pintores de la Edad Moderna, pues no fue descubierto hasta 1831 en la exedra de la Casa del Fauno. ${ }^{17}$ Sin embargo, sí que debieron de saber que ésta fue la escena representada

15 Plinio el Viejo, Naturalis Historia, XXXV, 110.

16 GARCIA Y BELLIDO, Antonio, Arte romano, CSIC, Madrid, 1979, pp. 159 y 160.

$17 \mathrm{El}$ análisis más completo hasta la fecha sobre la iconografía de este mosaico pompeyano sigue siendo el estudio de COHEN, Ada (1997), The Alexander mosaic. Stories of Victory and Defeat, Cambridge University Press, Cambridge. 

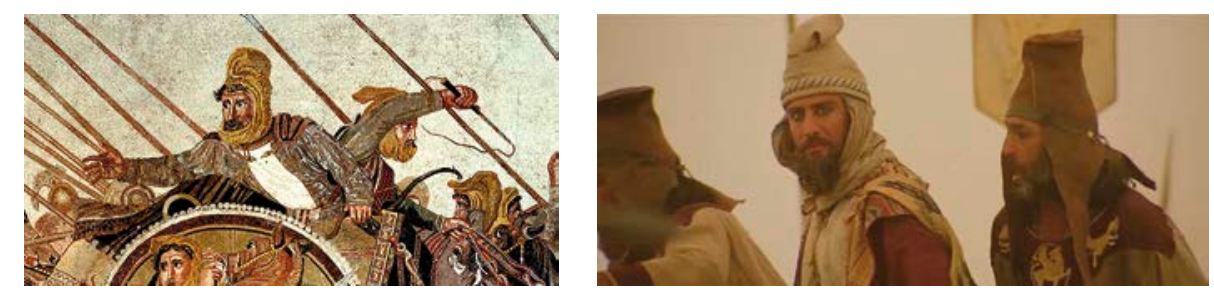

Figs.- 3 y 4 . Detalle de Darío huyendo en el mosaico y el filme de Stone.

en las obras desaparecidas sobre la batalla de Isso citadas por los clásicos. Y pudieron saberlo o bien por fuentes literarias o bien por otras representaciones que si sobrevivieron a la caída del Imperio Romano y a la larga Edad Media, como el relieve que decora uno de los laterales del llamado Sarcófago de Alejandro de Sidón (mármol pentélico, hacia el 310 a.C., Museo Arqueológico de Estambul), donde contemplamos posiblemente al joven conquistador montado sobre Bucéfalo y rodeado de sus generales cargando contra la caballería y la infantería persa. ${ }^{18} \mathrm{O}$ la pintura cerámica del ánfora atribuida al pintor de Darío o su taller (hacia 330 a.C., Museo Nazionale Archeologico, Nápoles), que muestra a Alejandro persiguiendo al rey persa. En cualquier caso, y mientras el mosaico permanecía oculto bajo las lavas del Vesubio hubo diversos artistas que recrearon en el Renacimiento y en el Barroco una de las dos grandes batallas que enfrentaron a Alejandro y Darío. Su identificación en ocasiones se presta a confusión, pues ya se trate de una $u$ otra se centran en el instante preciso en el que Alejandro arrolló con su carga a sus enemigos poniendo en fuga en ambas ocasiones al rey de Persia. En todas ellas el paisaje es inventado y no da pistas obviamente sobre si nos encontramos en Cilicia o en Mesopotamia. Y tan solo la presencia del mar o de la costa puede permitirnos afirmar que se trata de Isso y descartar Gaugamela. La insistencia en todas ellas en mostrar a Alejandro montado en Bucéfalo persiguiendo el carro de Darío es lógica puesto que este episodio concreto destaca la determinación del héroe que se pretende evocar, ya manifestada al llegar a Asia y cortar impetuosamente el nudo Gordiano. Pero también es útil para dejar claro quién es el vencedor indiscutible. Por estas razones se omite la que fue la primera gran batalla campal entre macedonios y persas, Gránico (334

18 MANFREDI, Valerio M. (2010), La tumba de Alejandro. El enigma, Grijalbo, Barcelona, pp. 135-163. 
a.C.), con la que el macedonio inició la conquista de Asia: porque aunque la dirigió y venció Alejandro, allí no estuvo Darío.

La primera pintura moderna que recrea el enfrentamiento personal entre el rey macedonio y el persa es la tabla pintada al óleo y temple por Albrecht Altdorfer en 1529 conocida como La batalla de Alejandro en Isso (Alte Pinakothek, Múnich). Pese a no ser muy grande es una de las obras de arte occidental que mejor evidencia el nivel épico y heroico que puede evocar la creación artística a la hora de representar una gesta guerrera. Y aun sorprende más su grandeza visual y su dimensión mitificadora si la situamos en su contexto y atendemos a sus circunstancias: no se trata de una pintura de alguno de los grandes artistas meridionales que en este momento triunfaban en las cortes del Renacimiento italiano, sino de un pintor bávaro poco conocido por esos años fuera de la ciudad de Ratisbona y sin apenas trayectoria previa en el género histórico o bélico. Pero la minuciosa e hipnótica recreación del momento álgido de la batalla, cuando Alejandro inicia su carga contra el corazón del inmenso ejército enemigo, el gigantesco paisaje marítimo y orográfico junto con la atmósfera celeste que envuelven el enfrentamiento -que evocan la creatividad de la llamada escuela del Danubio- y la preciosa técnica pictórica de un artista que fue capaz de renunciar al cargo de alcalde de Ratisbona para encerrarse durante un año a pintar una de las composiciones más sorprendentes de todos los tiempos, convirtieron esta obra en la recreación artística más relevante de la gesta alejandrina hasta el descubrimiento del mosaico pompeyano tres siglos después. ${ }^{19}$

Tras Altdorfer, otros pintores evocaron ya en el siglo XVII la carga de Alejandro en Isso o Gaugamela y la subsiguiente huida de Darío, destacando Jan Brueghel el Viejo con La batalla de Isso o de Arbela (1602, Musée du Louvre), Pietro da Cortona en el óleo sobre lienzo Batalla de Alejandro (h. 1635, Musei Capitolini, Roma) o Charles LeBrun, también en óleo sobre lienzo, Batalla de Arbela (h. 1669, Musée du Louvre, París). Este último lienzo de Charles Le Brun pertenece a una serie de cuatro grandes lienzos sobre las batallas de Alejandro Magno -Gránico, Arbela, Babilonia e Hidaspes- pintados por encargo del rey de Francia Luis XIV que fueron replicados en tapices y estampas. Las estampas fueron realizadas por el

19 Me he ocupado de esta pintura en MÍNGUEZ, Víctor (2017), "Altdorfer y la carga de Alejandro en Iso. Una batalla planetaria e intemporal contra Oriente", en FERRER MAESTRO, Juan José, KUNST, Christiane., HERNÁNDEZ DE LA FUENTE, David y FABER, Eike (eds.), Entre los mundos: Homenaje a Pedro Barceló/Zwischen den Welten: Ferstschrift für Pedro Barceló, Presses Universitaires de Franche-Comté, Besançon, pp. 479-503. Una versión avanzada en MÍNGUEZ, Víctor (2017), Infierno y gloria en el mar. Los Habsburgo y el imaginario artístico de Lepanto (1430-1700), Universitat Jaume I, Castellón, pp. 193-221. 
grabador Gérard Audran, y permitieron difundir las imágenes bélicas de la campaña asiática de Alejandro como no se había hecho hasta este momento. Cada estampa se acompaña de un lema y una sucinta explicación en francés y latín. La correspondiente a la batalla de Arbela o Gaugamela dice así: Digna orbis imperio virtvs ("La virtud es digna del imperio del mundo"). Ya en el arte contemporáneo las recreaciones de las batallas alejandrinas son prácticamente inexistentes. No obstante, contamos con la representación de Isso que a mediados del siglo XX realizó el pintor abstracto y expresionista Cy Twombly en su interesante obra Synopsis of a Battle (1968).

Las películas de Rossen y Stone son biopics con un planteamiento similar. Aunque la primera ofrezca una estructura lineal desde el nacimiento a la muerte del conquistador y la segunda sea un relato memorístico de un Ptolomeo ya envejecido que recuerda los años que compartió con Alejandro, ambas ofrecen biografías paralelas y convencionales de la vida de éste. En la versión de Stone, una vez Ptolomeo empieza a contar la historia de su amigo, compañero y rey -a excepción del episodio referido a la muerte de Filipo narrado en flashback-, mantiene también una estructura ordenada del relato, desde el nacimiento a la muerte del macedonio. Las dos películas por lo tanto muestran en su primera parte el ascenso a la gloria del joven Alejandro y en la segunda -más breve en la versión de Rossen-sus perfiles más oblicuos y polémicos -la autodivinizacion, la tiranía, la crueldad, etcétera-. El episodio climático en ambos relatos cinematográficos es la batalla de Gaugamela, su victoria definitiva sobre Darío y la que le permite entrar vencedor en Babilonia -y a partir de este momento caer en las seducciones corruptoras de Oriente-. Hasta la recreación de la batalla ambos relatos van encadenando episodios que revelan poco a poco la grandeza futura y sin par de Alejandro. En la versión de Stone una elipsis omite todas las batallas que tienen lugar en Asia desde que el macedonio cruza el Helesponto hasta Gaugamela. En la versión de Rossen se representan cabalgadas e incendios de ciudades en la conquista de Grecia y de Asia. De la primera guerra contemplamos la batalla de Queronea, liderada por Filipo y en la que participa Alejandro. Y de la campaña de Asia se incluye Gránico -pero se omiten Tiro e Isso-. Tanto en Queronea como en Gránico vemos a Alejandro luchando en persona valientemente en el corazón del combate. En ambas películas, y especialmente en la dirigida por Stone, Gaugamela marca el momento en que Alejandro conquista por fin la ansiada gloria que lleva persiguiendo toda su vida.

La película de Rossen se inicia con imágenes de la conquista de las ciudades griegas por parte de Filipo de Macedonia. Una noche que éste está durmiendo en el campamento un soldado enviado por su esposa Olimpia 

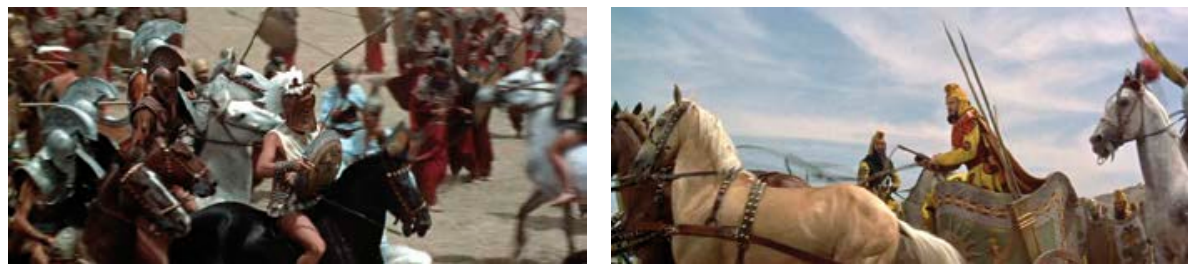

Figs.- 4 y 5 . Alejandro y Darío en el filme de Rossen.

le anuncia que es padre: "ha nacido un Dios", son las palabras que en boca del soldado traslada la madre. Cuando Filipo regresa a Pella un adivino egipcio le anuncia que el alumbramiento ha ido acompañado de prodigios. A continuación encontramos a Alejandro ya adolescente junto a sus compañeros practicando juegos físicos y aprendiendo al lado de Aristóteles. En un momento determinado, Alejandro se enoja porque su padre no quiere llevarle a la guerra, y le acusa de querer atesorar toda la gloria sin compartirla; Aristóteles le replica que ha hablado como un rey, que el imperio persa es un mundo, y que ésta reservado para él; Alejandro añade que, como a Aquiles, tampoco a él le importaría morir joven a cambio de alcanzar la gloria. En una escena posterior la voz de Aristóteles explica a Filipo las cualidades excepcionales de su hijo, para concluir que es un hombre mortal que se cree un Dios. Este relato imparable y mitificado hacia la grandeza y la fama de Alejandro se ve empañado no obstante por los continuos enfrentamientos entre su desconfiado padre y su posesiva madre, que le obligan continuamente a tomar partido viendo frenadas sus aspiraciones, retrasando una y otra vez su incorporación al gobierno y a la guerra, y frustrando su insaciable hambre de gloria. Cuando su padre le nombra regente de Pella ante la corte macedónica le da un consejo: tiene que aprender a estar solo. Ya en Asia cortará el nudo gordiano poniendo en evidencia su inevitable destino: no pierde ni un segundo en intentar deshacerlo antes de romperlo de un tajo. La impaciencia que ha marcado su juventud en la primera parte de la película le sigue acompañando en cada fotograma.

La película de Stone arranca con la recreación de la muerte de Alejandro en su palacio de Babilonia en el 323 a.C., para a continuación, trasladarnos cuarenta años después al palacio de Ptolomeo I en Alejandría, donde el viejo camarada del conquistador macedonio inicia la evocación de su vida dictándosela a un escriba. En estos primeros tres minutos de la película y a través tan solo de las palabras del anciano Ptolomeo se perfila con eficacia la imagen mítica de Alejandro. Según su camarada el rey macedonio fue un Prometeo, hijo quizá de Dionisos o de Zeus, una fuerza de la 
Naturaleza, unió y cambió el mundo, hizo que todo fuera posible, creo un imperio de inteligencia y las tribus se convirtieron en la civilización helenística. Este dibujo idealizado es reforzado con diversos episodios sucesivos de su infancia y adolescencia, y de nuevo contemplamos a Alejandro junto a sus compañeros en el gimnasio de Pella o asistiendo a las clases de Aristóteles. La doma de Bucéfalo, la reivindicación de Aquiles o el vuelo del águila jupiterina son los testimonios del increíble destino que le aguarda. Finalmente una elipsis nos traslada de la boda de Filipo con Eurídice en el palacio de Pella a la llanura de Gaugamela donde va a tener lugar la batalla. Solo la voz de Ptolomeo nos informa de todo lo sucedido en esos años que omite el relato: la muerte de Filipo, el sometimiento de Grecia, el cruce del Helesponto, Tiro, Egipto, etcétera.

El conveniente asesinato de Filipo a manos de Pausanias tras divorciarse el primero de Olimpia, volver a casarse con una princesa macedonia y engendrar otro heredero, convierte a Alejandro finalmente en rey -en ambas versiones se desmarca a éste del regicidio, pero el montaje cinematográfico de ambas permite albergar alguna duda sobre su responsabilidad en el mismo, y en la de Stone se apunta claramente a Olimpia como participante en la conspiración-. Sin embargo, en este instante de su vida Alejandro aún no ha demostrado nada, no se ha ganado la admiración de sus súbditos ni el respeto de sus enemigos. Sigue siendo un cazador de gloria bajo la sombra del recuerdo de su exitoso padre. En la versión de Rossen, todavía en Asia y después de varias victorias, aun le oímos gritar " ${ }_{\mathrm{i} N o}$ soy mi padre!". En la de Stone exclama esta misma frase en el mismísimo palacio de la ya conquistada Babilonia. En ambas películas, el momento de demostrar su valor y su grandeza y de superar definitivamente a Filipo es la batalla de Gaugamela. En la versión de Stone la voz de Ptolomeo presenta esta jornada como el día que Alejandro había esperado toda su vida. Y en ese momento solo tenía veinticinco años.

La batalla de Gaugamela en la película de Rossen se inicia la noche anterior a la misma, cuando Alejandro contempla las luces del inmenso campamento persa bajo una Luna Llena. A continuación, visitamos las tiendas y hogueras de ambos ejércitos. Los persas y sus aliados pasan la noche en tensión prestos a la batalla, mientras griegos y macedonios descansan. Darío III se limita a desfilar entre los vítores de sus soldados y rezar a sus dioses; mientras, Alejandro rechaza los malos agüeros, hace un sacrificio a sus propias divinidades, y arenga a generales y soldados. A la vez que le oímos exponer el plan de batalla llega el día, y contemplamos a ambos ejércitos desplegados uno frente al otro. Se inicia la batalla propiamente dicha. En primer lugar se produce la carga de los carros persas, que con sus hoces en las ruedas pretenden segar a la infantería griega, pero la falange 
se abre engulléndolos y les da muerte al otro lado. A continuación Alejandro inicia la carga de la caballería contra la infantería asiática. En pleno choque Alejandro arroja su lanza derribando al conductor del carro de Darío, que asustado toma las riendas y emprende la huida seguido por parte de su guardia. En la última escena de la batalla Alejandro galopa con sus guerreros hasta encontrar abandonado el carro del rey persa. La escena siguiente nos lo muestra invadiendo la tienda de campaña real: promete a la reina respetarla, abraza a sus hijos y conoce a su hija mayor Roxana. A continuación tiene lugar la persecución incesante a Darío hasta que éste muere a manos de sus soldados. No hay entrada triunfal en Babilonia.
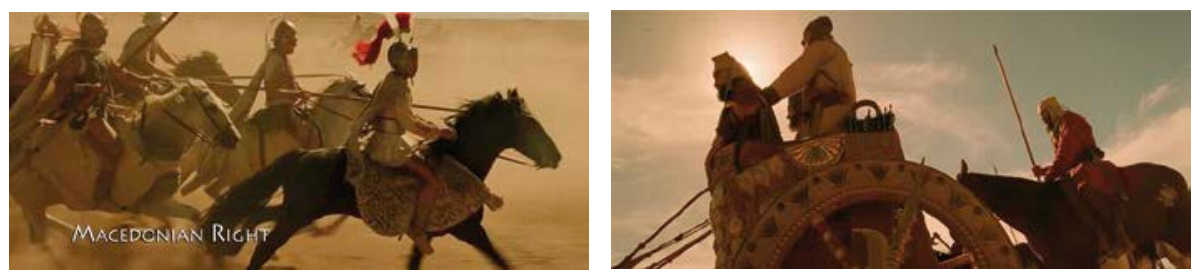

Figs.- 7 y 8 . Alejandro y Darío en el filme de Stone.

La batalla de Gaugamela en la película de Stone se aprovecha de las posibilidades del cine digital. Fue rodada con mil extras, pero en la pantalla se recrean con gran verosimilitud movimientos de contingentes militares muchísimo más numerosos. El paisaje desértico en el que transcurre es mucho más convincente que el más mediterráneo de Rossen. La primera imagen muestra a Alejandro sobre Bucéfalo contemplando en amplio campo de batalla y el inmenso ejército persa desplegado en él mientras el águila de su destino surca el cielo. A continuación lo vemos en su tienda planteando la estrategia a sus compañeros. Un eclipse de Luna tiene lugar mientras Alejandro visita las hogueras de sus soldados y confraterniza con ellos y abraza a Hefestión. El amanecer contempla a la falange macedónica ocupando sus posiciones, los sacrificios de los sacerdotes griegos y el discurso de Alejandro previo al combate a la vez que el águila sobrevuela ambos ejércitos: cita a alguno de sus soldados en persona, cuestiona a Darío, proclama que el suyo es un ejército de hombres libres frente a un ejército de esclavos y afirma que el valor vence a la muerte. A continuación Alejandro da orden de iniciar el movimiento envolvente de su ala derecha mientras la falange empieza a avanzar por el centro. Darío alarmado intenta contrarrestar la maniobra de Alejandro. El polvo que se levanta permite en un momento determinado que Alejandro junto con la caballería realice la 
carga en diagonal que les llevará al corazón del ejército persa. Mientras tanto las falanges del centro y la izquierda del ejército macedónico sufren ataques masivos de arqueros, carros, camelleros, caballería e infantería. De repente Darío, que dirige el movimiento de sus unidades gesticulando desde su carro contempla con estupor que Alejandro se halla frente a él y que le arroja una lanza. Inmediatamente da orden a su auriga de abandonar el campo de batalla. Alejandro inicia su persecución, pero tiene que abandonarla para ayudar al flanco izquierdo de su ejército, dirigido por Parmenio. Tras una escena nocturna en la enfermería asistimos a la entrada triunfal de Alejandro y su ejército en Babilonia, cruzando las puertas de Ishtar y avanzando por la avenida procesional entre zigurats, templos y jardines colgantes. La vista panorámica de la ciudad desde las terrazas de palacio fue obra del artista Steve Mitchell, que pintó un ciclorama de 50 metros de largo por 13 de ancho, con detalles casi microscópicos.
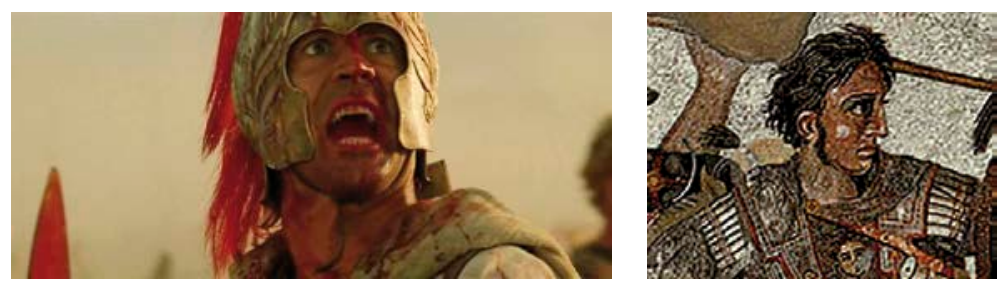

Figs.- 9 y 10. Detalle del rostro de Alejandro en el mosaico y el filme de Stone.

En ambas recreaciones de la batalla sobresale entre todas las cualidades de Alejandro su determinación: en luchar, en vencer, en seguir. Y esta determinación es la que también aflora aunque muda, en el mosaico pompeyano. En ambas películas Alejandro libra el combate portando un yelmo en la cabeza: de tipo hoplita en la versión de Rossen y un casco decorado con el león de Nemea asociado a Hércules en la de Stone. En el mosaico en cambio combate con la cabeza descubierta, y es la mirada obsesiva de Alejandro lo que revela su inquebrantable voluntad de vencer. En las películas su firmeza la ponen de relieve las palabras y la gesticulación. Y en todos los casos su incuestionable valor queda probado al encabezar la carga al frente de los compañeros.

Los compañeros o Hetairoi son otro elemento esencial del mito alejandrino recogido en el mosaico y popularizado en las versiones cinematográficas. Aunque dañados por la erupción del Vesubio y restauraciones infaustas se perciben en las teselas pompeyanas tres de ellos cabalgando junto al rey macedonio. Y por supuesto en ambas versiones cinematográficas galopan 

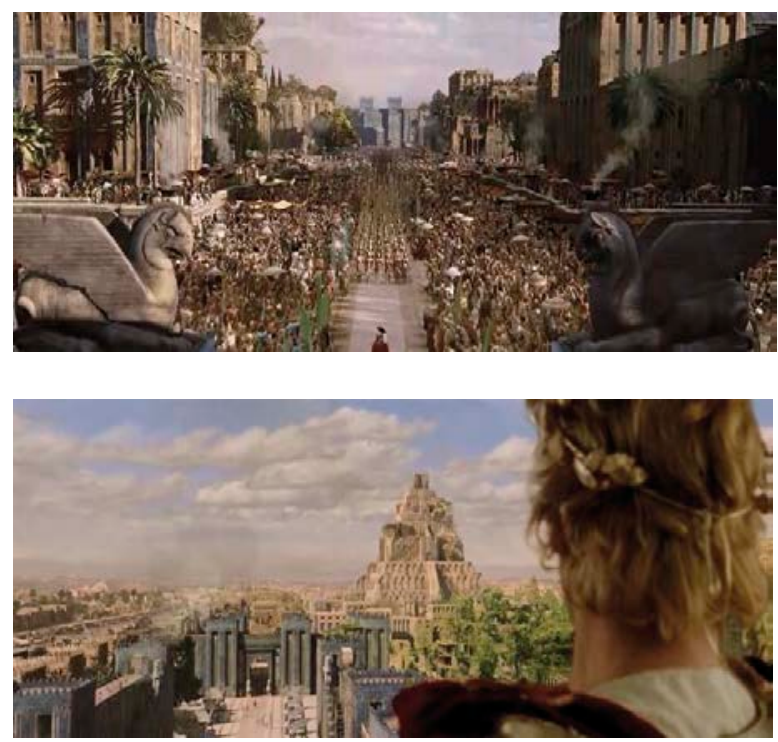

Figs.- 11 y 12. La entrada triunfal en Babilonia y Alejandro contemplando la ciudad tras ella en el filme de Stone.
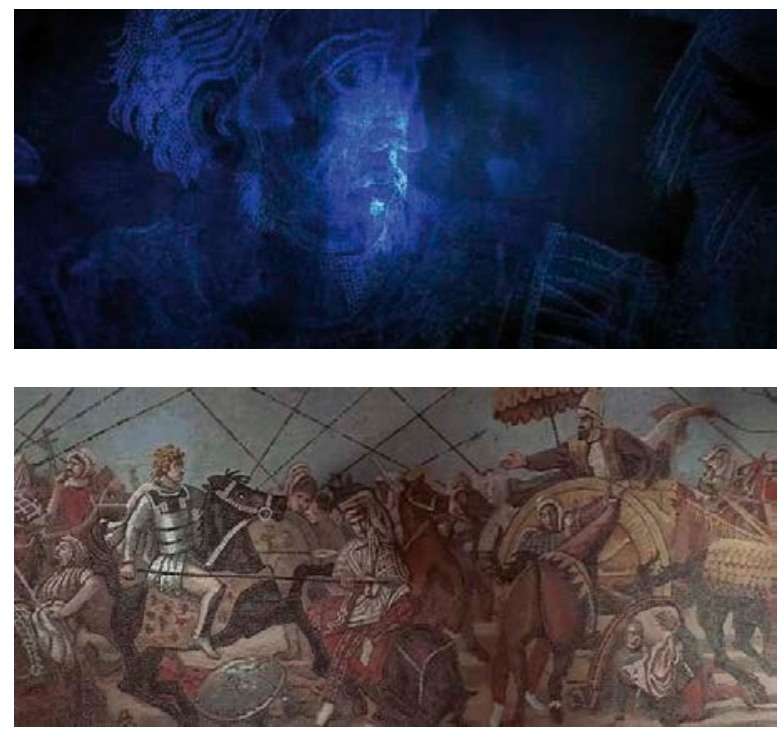

Figs.- 13 y 14. El mosaico en los títulos de crédito y la diégesis del filme de Stone. 
junto a Alejandro en el momento decisivo de la batalla. No son simples soldados de caballería, ni siquiera oficiales. Los Hetairoi eran los amigos y leales guardianes de Alejandro, escogidos entre los jóvenes más valientes de la aristocracia macedonia. Constituían el cuerpo más elitista de la caballería, pero eran ante todo camaradas de armas. En las dos películas que nos ocupan los vemos crecer junto a Alejandro, practicando con él gimnasio, asistiendo en grupo a las clases de Aristóteles, acompañándole en audiencias y festejos, firmes a su lado en los momentos difíciles, como cuando el futuro conquistador se enfrenta a su padre Filipo. $Y$ tras la muerte de éste, acompañándole en las campañas militares a lo largo de Asia o entrando triunfantes en Babilonia. $Y$ aunque algunos se convertirán en generales o sátrapas -y posteriormente en diádocos-, siempre están muy próximos físicamente a Alejandro, llegando en algún caso a amarse apasionadamente, como es el caso de Alejandro y Hefestión en la película de Stone, o más sutilmente en la pasión que Pausanias parece sentir por Alejandro en la película de Rossen. En ningún otro momento de la Historia un conquistador y sus generales -ni Ánibal, ni César, ni Napoleón- generaron una relación parecida de lazos afectivos tan estrechos, que se inspira sin duda en los cantos homéricos.

Ignoro si Rossen o Stone han tenido ocasión de contemplar el mosaico pompeyano en el Museo Nazionale Archeologico de Nápoles. Pero en cualquier caso éste forma parte del universo artístico popular hasta el punto que las teselas del rostro de Alejandro se han convertido en su imagen más conocida. En este sentido resulta revelador que ésta sea una de las imágenes que percibimos de fondo en los títulos de crédito iniciales de la película de Oliver Stone, y que sea la última que aparece en los créditos finales. Y aún más que cuando Ptolomeo inicie la biografía oral de Alejandro lo haga ante una representación del mosaico que decora en la película una pared de su palacio de Alejandría -significativamente igual que en el museo napolitano, y no en el suelo como fue hallado en realidad en el siglo XIX-. 